\title{
Emergence Time Phasing for the Potential New Airports in the Middle District of Iraq
}

\author{
Baraa Raad Mohammed $^{1 *}$, Muyasser Mohammed Jomaah ${ }^{1}$, Raquim Nihad Zehawi ${ }^{2}$ \\ ${ }^{1}$ Department of Civil Engineering, College of Engineering, Tikrit University, Tikrit 34001, Iraq \\ ${ }^{2}$ Department of Airport Engineering and Transportation Engineering, University of Diyala, Baquba 32001, Iraq
}

Corresponding Author Email: Baraa_raad@yahoo.com

https://doi.org/10.18280/ijdne.160504

Received: 23 August 2021

Accepted: 24 September 2021

\section{Keywords: \\ Baghdad international airport, Diyala governorate, al-Anbar governorate, salah al- din governorate, Baquba airport Habbaniyah airport, Balad airport, system dynamic}

\begin{abstract}
With the growing demand for air transportation and limited capacity at Baghdad International airport (BIAP), there is a need to increase the capacity of airport systems in the middle district of Iraq. The increased use of secondary airports has been and is expected to be one of the key mechanisms by which future demand is met in congested metropolitan areas. This paper analyzed the factors influencing the emergence of secondary airports in the Iraqi middle district and the dynamics of multi-airport systems. A system dynamics model was developed to simulate the relationship between the core airport in Baghdad and three potential secondary airports, one in each adjacent governorate. The model takes under consideration such characteristics as; capacity, location, proximity to populated communities, and ground transportation services for each airport. the main outcomes of this model are; the passenger's persuasion in an airport, which reflects their propensity to use this particular airport, and the predicted number of annual passengers in each airport. The system dynamics model was consulted twice. The outcomes of the first run facilitated the economic analyses of the secondary airports on which the sequence of the airports emergence was determined, and it also showed that the new airport feasibility is highly affected by the location, due to the influence on the road user cost for passengers, in addition to the capital expenses. The second run of the model helped in predicting the time schedule and interval between an airport emergence and the other. If the new airports have an equal capacity of one million passenger per year, the expected timing for the emergence is in 2023, 2027, and 2032 for the airports in Balad, Habbaniyah, and Baquba respectively.
\end{abstract}

\section{INTRODUCTION}

The appearance of the secondary airport is to regulate the main market economic regulation means for regulating the traffic and mitigation of tourists in major airports. Airports are an essential part of the transportation infrastructure in Iraq and play a substantial role in the local economy and community development [1]. These facilities' high quality of service is essential to ensure safe, cost-effective, and daily traffic operations [2]. There has been a rapid growth in the population of Iraq, leading to an increase in demand in every aspect of our lives. Therefore, the increase in demand is directly proportional to the increase of the usage of airports capacity. Airports in Iraq need to be reconsidered, and plans should be prepared to improve the quality of service of these facilities. The destruction of the US military's occupation and the damage of terrorist attacks the common airports in Iraq like Salah al-Din, Diyala, Al-Anbar airports alerted the engineer's transportation. It is of great concern for traffic engineers and planners to understand and evaluate the quality of service provided by airport facilities. With the growing number of vehicles, the quality of service decreased [3]. It became necessary to study the causes of the problem and find the appropriate solutions, either for the current or future conditions. Jrew et al. studied the main multilane airport highway in Baghdad, including Al- Dora intersection to AlRashid interchanges. The poor level of service of the airport's highways increased the traveling time, thereby increasing the amount of consumed fuel, thus lifting the traveling cost for highway users. Previous attempts predicted the passenger demand for a domestic airport. Barros et al., 2013 studied the consumer preference between airline types in Turkey. $\mathrm{He}$ found that age was a predictor of preference [4]. Mehta et al. 2019 found significant differences in passenger willingness to fly corresponding with risk assessment between males and females when presented with the scenario of cabin depressurization [5]. Farzane, 2010 forecasted the average daily number of passengers on transatlantic flights for each month from January 2000 to December 2010 [6]. Wai et al. 2014 employed the Box Jenkins Seasonal ARIMA (SARIMA) model and the ARIMAX model to forecast airport passenger traffic for Hong Kong and projecting its future growth trend to 2015 [7].

Predicting the expected number of passengers and the emergence of new airports in Iraqi airports was not yet done. This study was an early attempt to propose the probability of emerging new airports in the middle region in Iraq, specifically in Salah Al-Din, Diyala and Al-Anbar governorates. The system dynamics of a modeling tool are based on systems thinking approach; hence, it can model complex systems using feedback processes. As a modeling tool, system dynamics allows us to visualize a system as a feedback process in a causal loop and stock and flow diagrams [8]. System dynamic was used as a predictive mean in civil 
engineering [9-17]. The expected number of passengers for the emerged airports for the prospectus 15 years was predicted using the system dynamic based on the passengers persuasions and demographic changes of the airports.

\section{DATA COLLECTION}

The data collection process was exceptional and complicated. The accuracy and credibility of any planning study were highly dependent upon the reliability of the collected data. The data in this study were collected from the Central Organization for Statistics and Information Technology (COSIT) in Iraq and the Ministry of Planning for Salah Al-Din governorate, including the population growth from 2010 to 2018. Demographic and socioeconomic characteristics on a national, regional, provincial, or local scale were also included. The data was essential when socioeconomics was utilized as explanatory parameters in developing the prediction model for air travel demand [18]. Baghdad International airport (BIAP) was considered the core airport (original airport) because it is the only functioning airport in this district. All the aviation data regarding passenger movements and aircraft operations performed in this airport was collected appropriately. The locations of the abundant airfields, which mostly have military background, were considered as potential airports for emergence in the near future; these potentials are; Ramadi, Habbaniyah, and Rutba in Al-Anbar governorate and Baqubah, Salum, and Subakhu in Diyala governorate and Balad, Tikrit and Samarra in Salah Al-Din Governorate. Google earth was used to illustrated the airports locations in the governorates as depicted by Figure 1. Table 1 shows the distribution of the airports in the governorates. All the pertaining data for each airfield was collected, including location, available infrastructures, ground access availability [19-21].

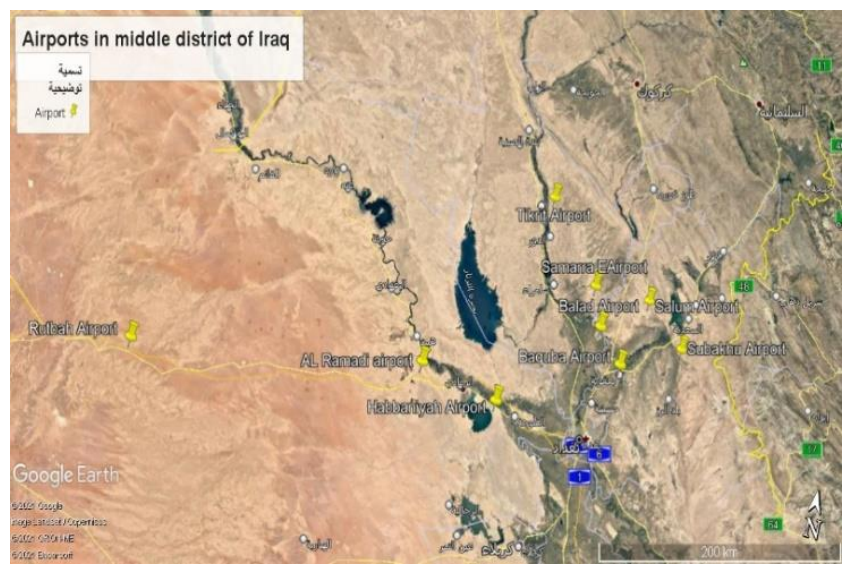

Figure 1. The location of the airports in the middle region of Iraq

Table 1. The distribution of the airports in the governorates

\begin{tabular}{cc}
\hline Airports & Governorate \\
\hline Balad & \\
Samarra & Salah Al-Din \\
Tikrit & \\
\hline Baquba & \\
Salum & Diyala \\
Subakhu & \\
\hline Habbaniyah & Al-Anbar \\
\hline
\end{tabular}

\section{DATA ANALYSIS}

As in many local and international studies, the population is an important factor in air travel demand modeling [22, 23]. The aviation demand is highly expected to directly correlate to the population $[24,25]$ either in the middle district or all over the country.

The extrapolated population for the middle region of Iraq is presented in Figure 2. It is demonstrated that the population was considerably increased for the selected region from 2010 to 2018. Therefore, the aviation demand in the middle region is expected to increase as well. The percentage of travelers to the population is constantly changing through the period from 2010 to 2018, the pattern of change in this percentage resembles the exponential smoothing which is bonded to an upper asymptote that will not be reached as illustrated in Figure 3. which reveals that the future estimation to this percentage is ranging between $25 \%$ to $30 \%$. The adopted percentage value was considered to be constant at $28 \%$ for the future estimations as demonstrated by Figure 3 . Figure 3 shows the passenger to population ratio from 2010 to 2038 . It is dementated from Figure 3 that the passengers to population ratio ranged in $24 \%$ and $32 \%$, thus the average ratio between them was taken as $28 \%$ [26].

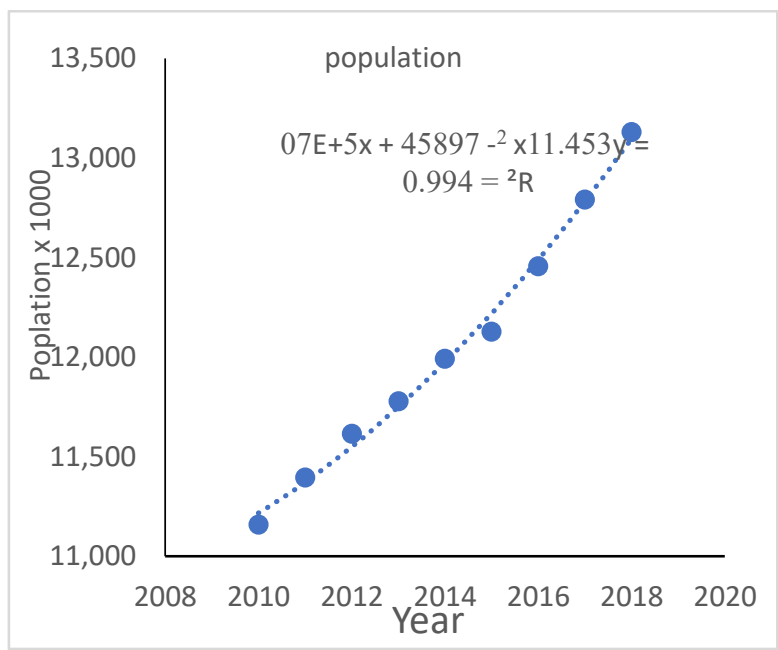

Figure 2. Population extrapolation for the middle region of Iraq

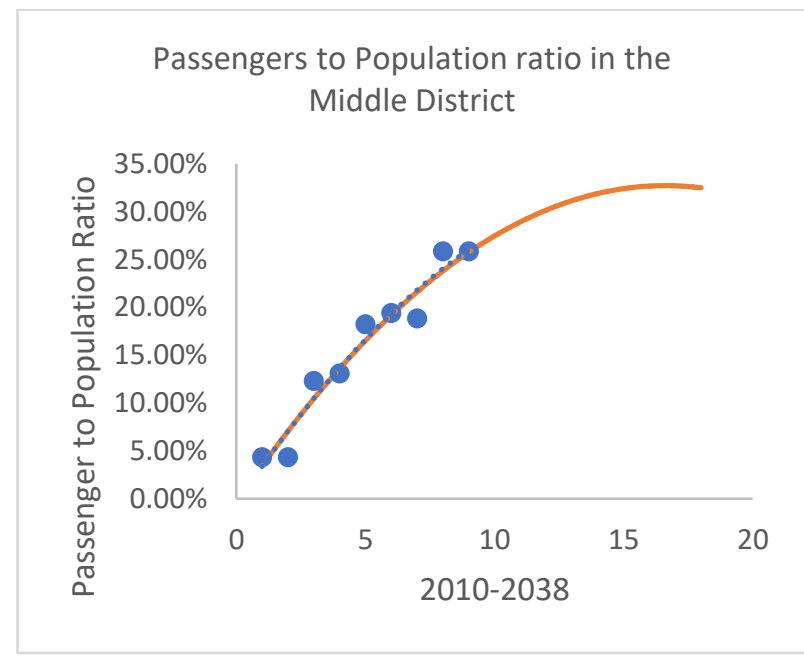

Figure 3. The percentage of travelers to the population from 2010 to 2038 
The terminal's original annual capacity of Baghdad International Airport is about 7.5 million passengers per year, comprised of three identical adjacent buildings. The capacity of each one of them is 2.5 million passenger per year. It is expected that the congestion will start when the annual passengers reach $80 \%$ of the current capacity, like 5.25 million passengers per year, and continue to increase until saturation. As in many similar cases, the expected pattern of terminal behavior is to follow a logistic shape, as illustrated in Figure 4 [27]. The resemblance, in this case, lies mainly in the fact that when the core airport (BIAP) reaches saturation, it is highly expected that a secondary airport will emerge to fill the gap and accommodate the access demand [28]. This new airport is expected to emerge near the trip generation communities located far from the core airport mostly due to economic, social, and even political reasons, especially when these communities have their administrative authorities.

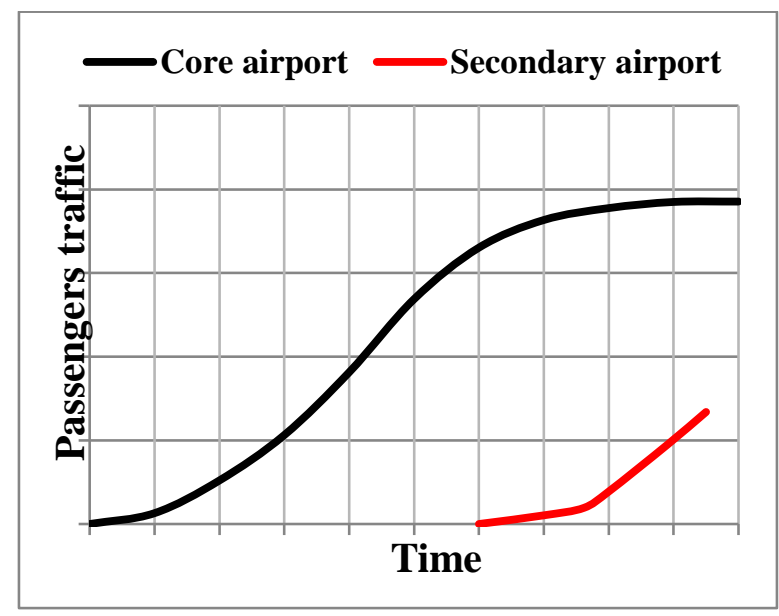

Figure 4. Expected scenario of the new airport emergence

\section{SYSTEM DYNAMIC MODEL}

The purpose of the system dynamic models in this study is summarized as follows:

- Illustrating the dynamic behavior of the air travel demand when more than one airport is available to the group of passengers within a homogenous district such as the middle region of Iraq.

- Creating appropriate tools by which many scenarios can be analyzed and examined. These scenarios may represent all the applicable and reasonable possibilities of new commercial airports within the same market area and their impacts on the existing airport.

- Testing the plausible policies adopted by the parties to predict the most applicable strategy satisfies the expected demand throughout the planning period.

\subsection{Basic system dynamic model}

The basic system dynamics model was developed to simulate the behavior of the airports expected to emerge in the middle sector of Iraq, which comprises three governorates. At first glance, each one of these governorates has its defined airports. Each of these airports was linked and examined against Baghdad international airport (BIAP) by implementing the novel dynamic simulation models.

The outcomes of this basic model should suggest the most applicable airport to emerge among the nominees within each governorate. This suggestion is made depending on the expected persuasion and consequently the expected number of passengers.

In the basic model, the presence of one airport in a certain governorate is proposed to reveal the dynamic relations and interactive relations between the two airports in the basic system made up of the core and the new emerging ones.

The main causality in the basic model consists of two balancings (negative) loops that describe the competition between the newly emerging airport (see Figure 5), in which the terminal facility is still underutilized and the core airport. In the new airport, the passengers are not experiencing any delay, which may represent a great encouragement to use this airport instead of the old and congested one, but at the same time, the reputation of the new airport is not widely spread, and it is hard for any passenger who used to travel from a certain airport to change this choice easily.

As the passenger number in the core airport grows up to approach the terminal capacity and delay starts to increase for many passengers, their views regarding the use of the new airport start to increase, and gradually many passengers will gradually be transferred from the core airport to the new one.

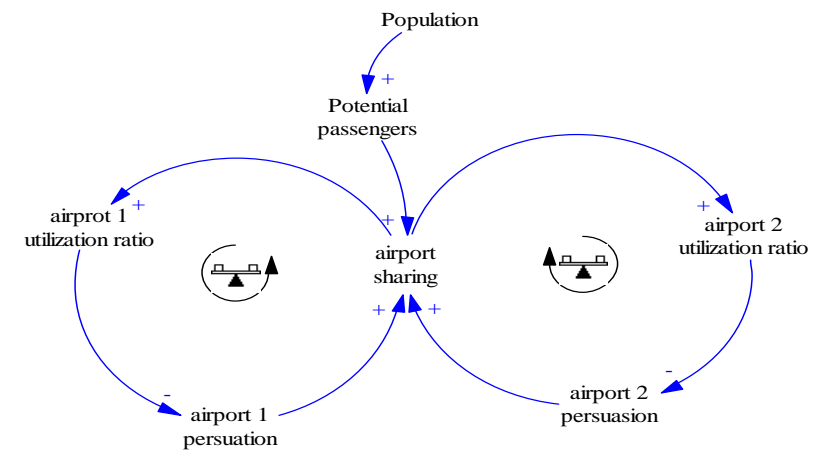

Figure 5. Causal loops in the basic model

\subsubsection{Basic model stock and flow diagram}

The stock and flow diagram for the basic model consists three stocks (levels), which represent the accumulation processes for the population of the district, the persuasion of the core airport, and the persuasion of the secondary or emerging airport; these persuasion levels should represent the extent to which the passengers are convinced in using this particular airport. As explained later, each level characterizes the core variable for a sub-model along with the exogenous inputs and pertaining auxiliaries (Figure 6).

\subsubsection{Population sub model}

The population sub-model is built in an abstract context due to the steady and easily predicted growth for the last four decades in the middle district of Iraq. The normal growth in the population of any community is the net difference between the births and deaths on the one hand and the net difference between the in-migration and out-migration. In some cases, when the steadied phenomena may affect any of these variables, such as deaths or migration, it would be necessary to have them included in the model. However, if the simulated variables do not affect any one of these factors, as in this study in which the air travel passengers have no such effect on either death, birth, in or out-migration, there is no need to introduce them in the model, but only the net growth of the combined population of the four governorates is used. 


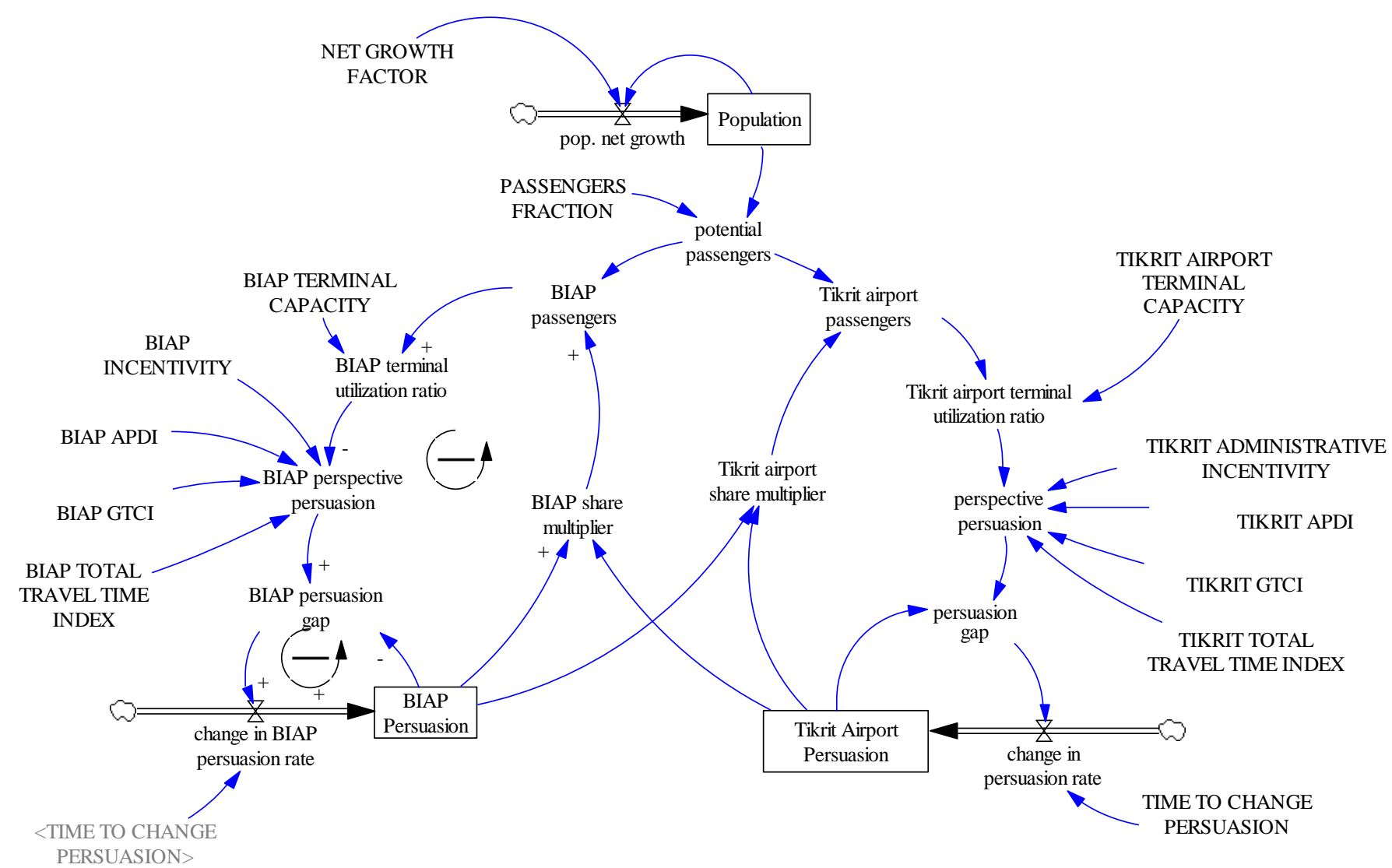

Figure 6. Stock-Flow diagram for the basic model

According to the Iraqi Central Statistical Organization population reports, the combined population of the four governorates comprising the middle district in Iraq is steadily fixed around $(2.04 \%)$ along the past two decades and its strongly expected to keep this way for no less than two more decades to come (25).

According to the previously mentioned information, the population sub model is composed of the following:

First; levels

- Population: this level accumulates the rate "Pop. net growth". The initial value of this stock is the district's population in 2010 , which is $(11,159,300)$ as reported in the Ministry of planning and the central division for statistics.

$$
\begin{gathered}
\text { Population= } \\
\text { INTEG ("pop. net growth", } \\
1.11593 e+007)
\end{gathered}
$$

\section{Second; rates}

- Pop. net growth: this rate stands for the increment in population number that occurred in unit time according to the constant "NET GROWTH FACTOR" equal to (2.04\%) as stated earlier.

$$
\begin{gathered}
\text { "pop. net growth"= Population*NET GROWTH } \\
\text { FACTOR }
\end{gathered}
$$

Third; auxiliaries

Potential passengers: this auxiliary calculates the number of potential air travel passengers as a fraction of the total population. This fraction was found to be nearly constant at about (0.28), as stated earlier.

$$
\text { potential passengers }=\text { Population } * \text { PASSENGERS }
$$$$
\text { FRACTION }
$$

\subsubsection{Core airport persuasion sub model}

The core airport in this study is the Baghdad International Airport (BIAP) in this basic model, and the main models are yet to be presented.

The core airport's persuasion starts with its maximum initial value because it's the only airport available to the passengers before the emergence of any new airport. This maximum value was estimated to be $95 \%$ because it represents a subjective matter which cannot be $100 \%$. This means that even when there is no other airport available in the district, a small percentage of local passengers prefer to use an external airport located outside the district and take the ground trip before a flight. Even when there was no other airport available in the district, a small percentage of local passengers prefer to use an external airport outside the district and take the ground trip before the flight, as demonstrated in Figure 6.

Figure 7 and Figure 8 show the simulation run of the basic model of Tikrit airport from 2010 to 2035; the persuasion of the airport within the province was constant for the first three years from 2010 to 2013 because the passengers will not be familiar with the new airports. The persuasion will significantly increase from 2013 until 2015 because the reputation of the airports will be spread among the passengers. It will become constant from 2020 to 2035 and continues to perform steadily state. The passenger's persuasion of BIAP decreased after the emergence of the new airports in 2010; it will decrease drastically for the first twelve years of the airport's operations due to the passenger's persuasions to the newly emerged airports. 


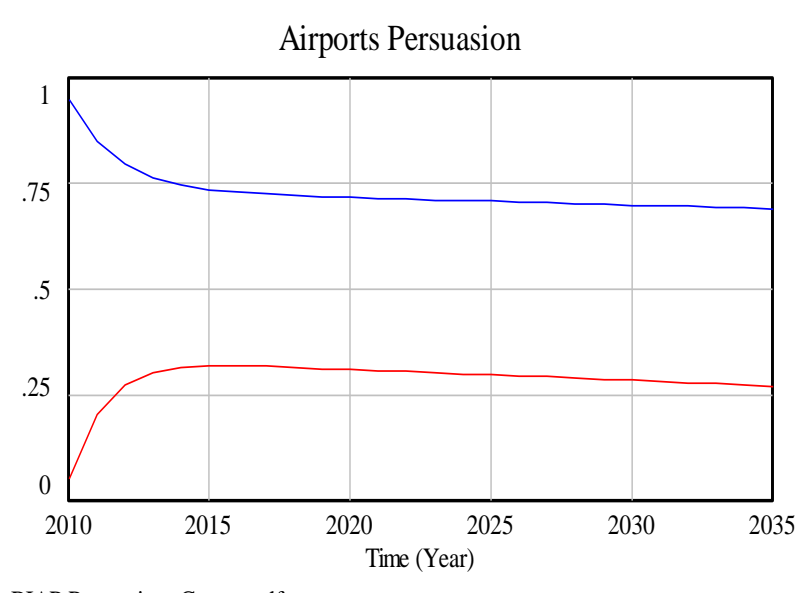

BIAP Persuasion : Current.vdfx

Tikrit Airport Persuasion : Current.vdfx

Figure 7. The Persuasion of passengers for BIAP and Tikrit Airport

\section{AIRPORT ANNUAL PASSENGERS}

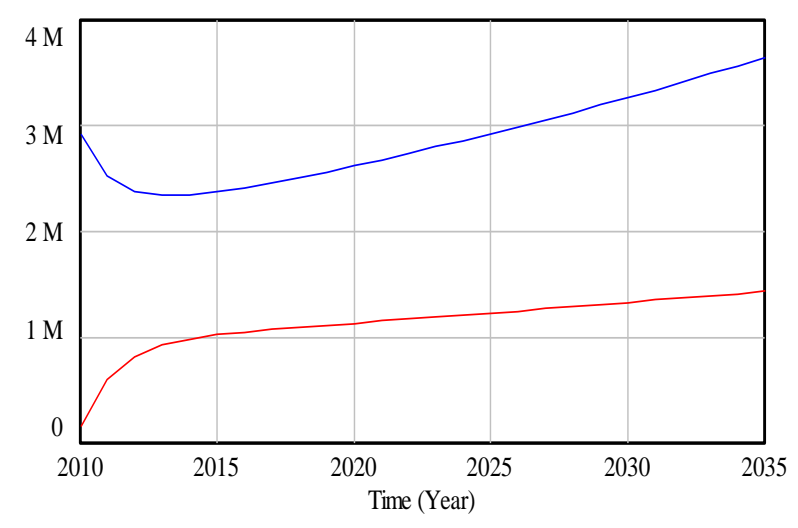

BIAP passengers : Current.vdfx

Tikrit airport passengers : Current.vdfx

Figure 8. The expected passengers in BIAP and Tikrit Airport

The sub model is comprised of a balancing loop with an information delay typical loop (see Figure 5). The components of these loops are as follows:

First; Levels

Core airport persuasion: this level accumulates the rate "change in core airport persuasion". It stands for the actual motivation between passengers to use this airport in particular.

$$
\begin{gathered}
\text { BIAP Persuasion }=\text { INTEG }(\text { change in BIAP } \\
\text { persuasion rate, } 0.95)
\end{gathered}
$$

\section{Second; rates}

- Change in core airport persuasion: this rate represents the change occurs in airport persuasion in unit time governed by the time constant "TIME TO CHANGE PERSUASION".

change in BIAP persuasion rate $=$ BIAP persuasion gap/TIME TO CHANGE PERSUASION

Third; auxiliaries

- Core airport persuasion gap: this auxiliary calculates the difference between the apparent or expected persuasion drone from the correlated variables and the actual persuasion grown gradually between passengers in the core airport. As stated earlier, the persuasion is a matter of subjective opinion that usually takes time to take effect what may represent a typical information delay sub model.

$$
\begin{gathered}
\text { BIAP persuasion gap }=\text { BIAP perspective } \\
\text { persuasion-BIAP Persuasion }
\end{gathered}
$$

- Core airport share multiplier: this multiplier represents the share of the core airport out of the total potential passengers. The share is estimated as the ratio between the actual persuasion of the core airport and the summation of the persuasion of all existing airport, in this case two airports, core and secondary one.

\section{$B I A P$ share multiplier $=B I A P$ Persuasion $/(B I A P$ \\ Persuasion + Tikrit airport Persuasion)}

- Core airport passengers: this auxiliary calculates the number of passengers using the core airport depending on its share multiplier. The mathematical relation for the Baghdad International Airport) is as follows:

$$
\begin{aligned}
\text { BIAP passengers }= & \text { BIAP share multiplier*potential } \\
& \text { passengers }
\end{aligned}
$$

Core terminal utilization ratio: this auxiliary represents the saturation degree of the terminal facility in the core airport, which is usually calculated by dividing the demand over the terminal capacity.

$$
\begin{gathered}
\text { BIAP terminal utilization ratio= BIAP } \\
\text { passengers/BIAP TERMINAL CAPACITY. }
\end{gathered}
$$

- Core airport perspective persuasion: the expected persuasion of the core airport should be calculated here. The estimated persuasion is derived from the factors influencing passengers' choices for airports regarding the ground distance traveled, ground journey cost, ground journey total time, and Incentivity of neighboring within the same governorate and the terminal utilization ratio. The latter is the endogenous factor and the most influential one, which was estimated to affect the opinion of passengers three times more than any other exogenous factor. The endogenous factor is calculated through Eq. (9), whiles the other four factors are introduced in this model as constants. Listed in Table 2.

$$
\begin{gathered}
\text { BIAP perspective persuasion }=((\text { BIAP } \\
\text { INCENTIVITY }+3 *(1-B I A P \text { terminal utilization } \\
\text { ratio })+(1-B I A P A P D I)+(1-B I A P \text { GTCI })+(1- \\
\text { BIAP TOTAL TRAVEL TIME })) / 7)
\end{gathered}
$$

The following constants are related to the influencing indices that differ according to the location, population, ground transportation availability in each airport governorate. - Core airport Incentivity: this factor is nearly constant in each governorate, for it is equal to the ratio of its population divided by the population of the whole district.

$$
\text { BIAP INCENTIVITY }=0.635
$$


- Core airport APDI "Average Passenger Distance Index" which may stand for the effect of the location of the airport and its relative proximity to the population concentration areas.

$$
\text { BIAP APDI }=0.2
$$

- Core airport GTCI "Ground Total Cost Index": this constant represents the effect of the weighted average of the cost paid by the passenger for the ground journey towards the airport location.

$$
B I A P G T C I=0.13
$$

Core airport TTTI "Total Travel Time Index": this constant stands for the weighted average total time spent by the passenger during the ground journey towards the airport location.

$$
\text { BIAP TTTI }=45 / 120
$$

\subsubsection{Secondary airport persuasion sub model}

The secondary airport in this basic model is Tikrit Airport while in the following model's many airports are introduced as secondary airports.

This sub-model is very similar to the previous one of the core airport sub model but with adopting the characteristics and indices of the secondary airport.

The persuasion of the secondary airport is starting with a minimum initial value because it is still new in service, and so many passengers have not tested it, unlike the core one. The initial persuasion value was estimated to be $5 \%$ to represent those enthusiastic for the local airport no matter how the service might be.

This sub-model also comprises a balancing loop with an information delay typical loop as in the core airport sub-model.

The equations of this sub model will be as follows:

$$
\begin{gathered}
\text { Tikrit airport Persuasion= INTEG (change in Tikrit } \\
\text { airport persuasion rate, } 0.05
\end{gathered}
$$

change in Tikrit persuasion rate $=$ Tikri persuasion gap/TIME TO CHANGE PERSUASION

Tikrit persuasion gap $=$ Tikrit perspective persuasion-Tikrit

Tikrit share multiplier= Tikrit Persuasion/(BIAP Persuasion + Tikrit airport Persuasion) $\begin{aligned} & \text { Tikrit passengers }= \text { Tikrit share multiplier*potential } \\ & \text { passengers }\end{aligned}$

Tikrit terminal utilization ratio $=$ Tikrit passengers/TIKRIT TERMINAL CAPACITY

Tikrit perspective persuasion $=((T I K R I T$ INCENTIVITY $+3 *(1-$ Tikrit terminal utilization ratio $)+(1-T I K R I T$ APDI $)+(1-T I K R I T$ GTCI $)+(1-$ TIKRIT TTTI))/7)

TIKRIT INCENTIVITY $=0.1157$

$$
\begin{gathered}
\text { TIKRIT APDI }=0.587 \\
\text { TIKRIT GTCI }=0.3
\end{gathered}
$$

$$
\text { BIAPTTTI }=0.952
$$

\subsection{The Iraqi middle district's model}

This model was designed to simulate a group of four airports, the core one in Baghdad and one in each governorate in the middle district. These airports were; Balad airport in Salah Al Din governorates, Baquba airport in Diyala governorate and Hubbaniyah airport in $\mathrm{Al}$ Anbar governorate. The same structure of the basic model was adopted in this model but with three secondary emerging airports instead of one. In this model, it was hypothetically presumed that the three airports in the middle of Iraq are to emerge simultaneously in 2020 and complete the construction and start its services in 2023 in order to determine which one of them is the most preferable among the others in terms of persuasion and future passengers. The constants in this model were TTI, GTCI, ADPI, Incendivity, and terminal capacity. They considerably influenced the passenger's persuasion towards middle district airports in this model. Table 1 lists the values of the influencing factors on the middle district and BIAP. Figure 9 shows the middle district model. It was assumed that three airports would emerge in the middle district in Iraq in 2020 and start its services in 2023.

The simulation run of this model showed that the passengers persuasion in BIAP is declining continuously from the start of the simulation in 2010 due to the fact that it is the only available airport with a fixed capacity while the demand is increasing and the terminal utilization ratio is increasing causing the inclination in persuasion in BIAP. This will relieve the congestion in the core airport and lower the utilization ratio in its terminal, which may increase persuasion after the year 2025 as shown in Figure 10 and Figure 11. As for all the secondary airports, the persuasion, as expected, starts to appear and grow rapidly immediately after their launch in service-driven mainly by the low terminal utilization ratio of the new airports. This growth reaches the peak within three years after the annual passengers reach the suggested capacity of the terminal building in each airport, which was assumed to be one million passengers per year. When the utilization ratio in the secondary airports approaches 1 , and the delay is extremely propagated, the persuasion is declined continuously.

The simulation of this model also shows that the Baghdad airport's annual passengers are steadily increasing after 2010 until the emergence of the new airports in 2023, when they are decreased substantially for the next 5 years of operation before steadily rising due to the arrival of these new airports to their terminal saturation as a result of the increase in the number of passengers as shown in Figure 12.

This simulation run of this model shows a very close similarity in the pattern of the growth of the passengers for each of the newly launched airports. This may suggest the resemblance in the selection process of these airports among other nominees in terms of the proximity to the trip generation community's, suitability of the location with respect to the governorate, and the appropriateness of the ground access. All these factors are reflected in the exogenous constants listed in Table 2 


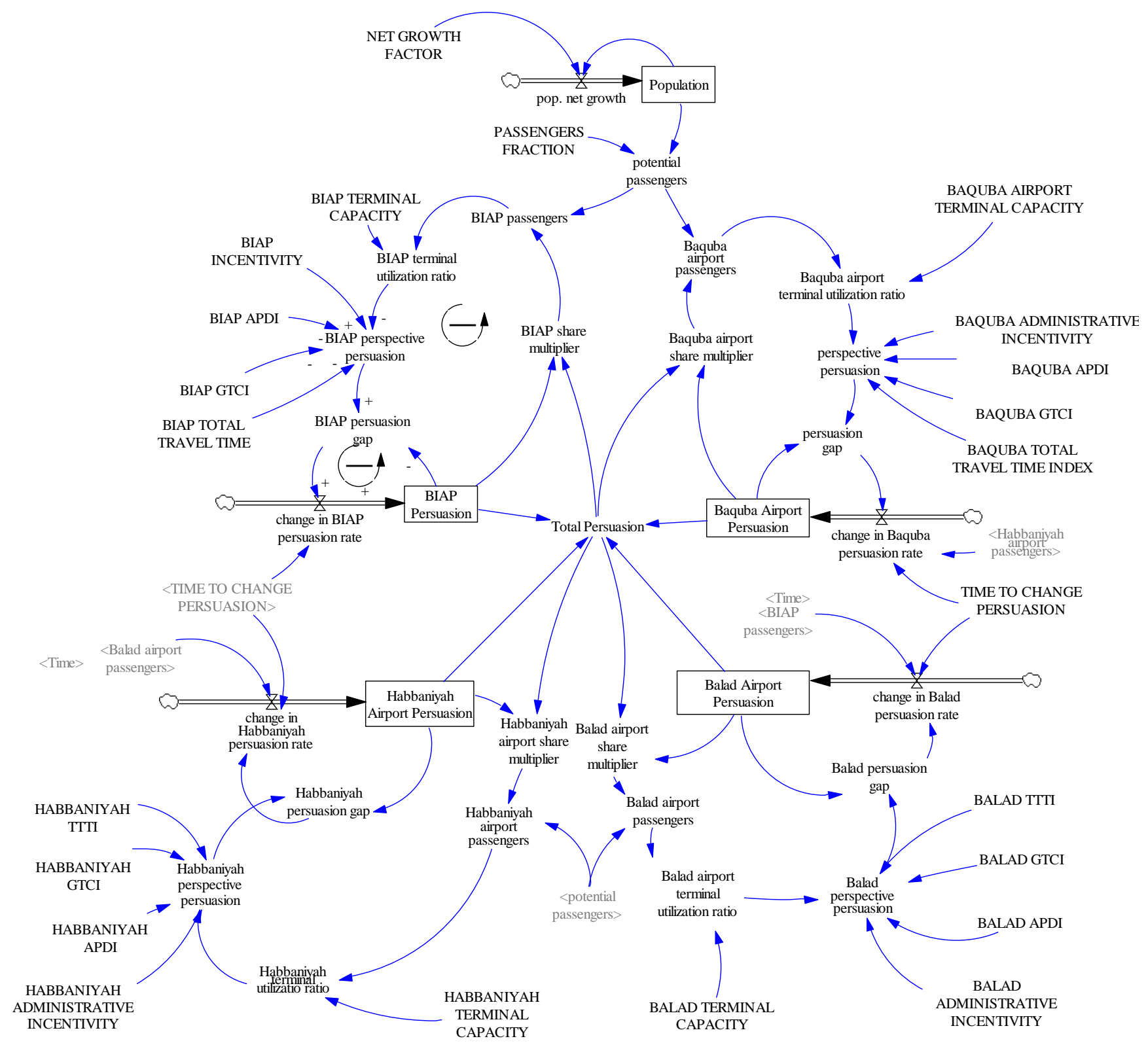

Figure 9. Basic model with best airport in middle of Iraq

Airports Persuasion

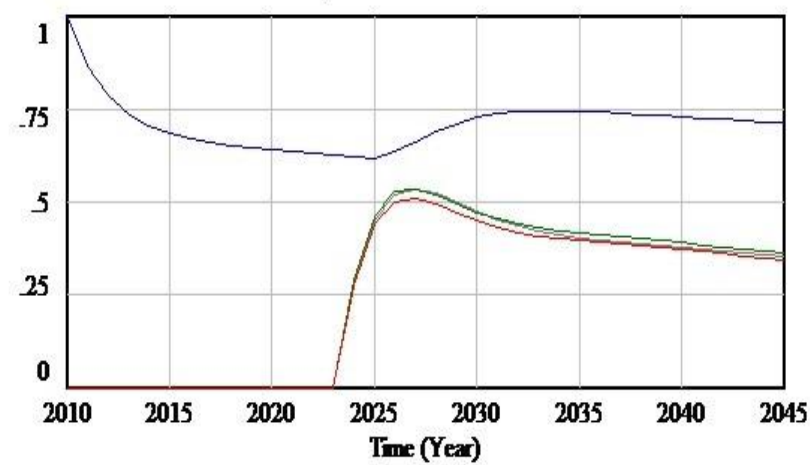

BIAP Persasion : Curentwifx

Balad Aiport Persuasion : Currentudix

Baqua Aiport Persiasion : Currentwix

Habbanigh Aiport Persasion : Curentudx

Figure 10. The persuasion of passengers in within (Baquba airport, Balad airport, Habbaniyah airport)
AIRPORT ANNUAL PASSENGERS

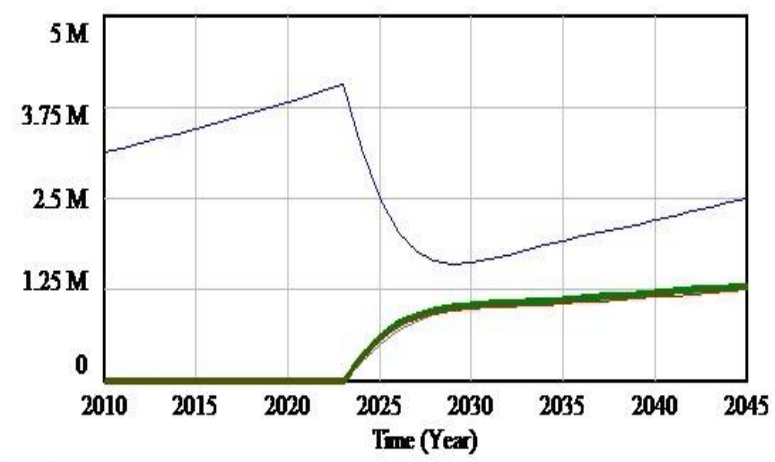

BIAP passengers : Cumentwdix

Babad aiport passengers : Curentvdix

Bapiba aiport passengers : Curentwifx

Habbanyzh aiport passengers : Currentwdix

Figure 11. The number of passengers in (Baquba airport, Balad airport, Habbaniyah airport) 
Table 2. The influencing factors on passengers persuasion middle of Iraq

\begin{tabular}{cccccccc}
\hline NO & Airport & Governorate & TTTI & GTCI & T. Capacity & APDI & Incentivity \\
\hline 1 & Baghdad & Baghdad & 0.396 & 0.130 & $7,500,000$ & 0.205 & 0.635 \\
2 & Habbaniyah & Al-Anbar & 0.667 & 0.17 & $1,500,000$ & 0.37 & 0.129 \\
3 & Baquba & Diyala & 0.601 & 0.149 & $1,500,000$ & 0.321 & 0.119 \\
4 & Balad & Salah Al-Din & 0.732 & 0.198 & $1,500,000$ & 0.378 & 0.116 \\
5 & Tikrit & Salah Al-Din & 0.952 & 0.300 & $1,500,000$ & 0.587 & 0.116 \\
\hline
\end{tabular}

Table 3. Expected number passengers

\begin{tabular}{ccccc}
\hline year & BIAP & Baquba & Balad & Habbaniyah \\
\hline 2023 & 3132826 & 317625 & 302524 & 258081 \\
2024 & 2443456 & 581416 & 553773 & 489976 \\
2025 & 1991166 & 763250 & 726963 & 668030 \\
2026 & 1730016 & 879318 & 837512 & 797072 \\
2027 & 1603776 & 949822 & 904664 & 887073 \\
2028 & 1565776 & 991543 & 944402 & 947851 \\
2029 & 1581266 & 1016816 & 968465 & 987927 \\
2030 & 1625996 & 1033936 & 984771 & 1014316 \\
2031 & 1684246 & 1048026 & 998189 & 1032486 \\
2032 & 1746726 & 1061846 & 1011366 & 1046516 \\
2033 & 1808656 & 1076636 & 1025446 & 1059166 \\
2034 & 1868206 & 1092716 & 1040766 & 1072136 \\
2035 & 1925206 & 1109956 & 1057186 & 1086286 \\
2036 & 1980326 & 1128116 & 1074476 & 1101916 \\
2037 & 2034496 & 1146906 & 1092386 & 1118936 \\
2038 & 2088616 & 1166156 & 1110716 & 1137116 \\
Total & $30,810,756$ & $15,364,084$ & $14,633,605$ & $14,704,884$ \\
\hline
\end{tabular}

Airports Persuasion

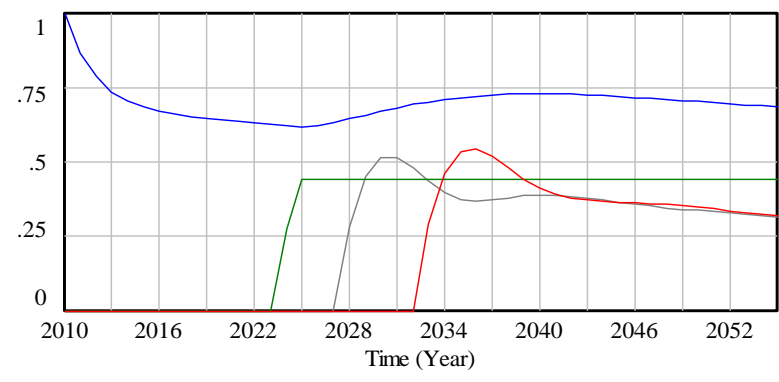

BIAP Persuasion : Current.vdfx

Baquba Airport Persuasion : Current.vd

Habbaniyah Airport Persuasion : Current.vdfx

Figure 12. Passengers persuasion best airport in the middle of Iraq model

It is worthwhile to re-state that the results mentioned above are based on the hypothetical simultaneous emergence of the three secondary airports, which is very unlikely due to the financial difficulty imposed on the national airports and aviation authorities. Table 3 lists the total cumulative number of expected passengers in Baquba, Balad, and Habbaniyah airports are; 15,364,084, 14,633,605, and 14,704,884, respectively for the period from 2023 to 2038 .

Passengers fraction $=0.28$, net growth factor $=0.0204$, Time to change persuasion $=2.5$ years.

\section{ECONOMIC ANALYSES}

The economic analyses conducted by assessing the total cost for each airport and then distribute it on the future passengers expected to be served within the next 15 years after the emergence. The most feasible one is that with the lowest cost per passenger ratio, referred to as the feasibility index.
The total cost represents the construction cost, annual maintenance and operational costs, and road user cost, all of which are discounted to the base year for the sake of equity between candidate airports in their comparison.

The total construction cost of each airport was calculated depending on the viable existing facilities in each location capable of functioning or needing some minor maintenance works. In some cases, the potential locations may be completely new, and the expected cost represented the complete construction of a new airport. The total airport costs are calculated in Table 4, which lists the required cost per element as the runway, taxiway, apron, terminal, and qualified ground access roads and the total cost for each emerging airport. Each airport's basic operational facilities cost was estimated according to the energy technology system analyses programs (ETSAP, 2011) [21]. The total area needed for each terminal facility per airport was assumed $25000 \mathrm{~m}^{2}$, for which the estimated construction cost is $\$ 61,200,000$. In contrast, other facilities vary in magnitude and capability from one airport to another, such as the runway considered acceptable if it is equal or greater than $3600 \mathrm{~m}$. if the available one is shorter, an extension is required at an estimated cost of $7200 \$ / \mathrm{m}$. The listed cost is the amount required to make each facility completely functional.

The maintenance costs for old airports were estimated according to the condition of their existing facilities, ranging from $\$ 200,000$ to $\$ 300,000$ annually. Baquba airport required the least maintenance cost compared with the other airports for it is the only one with all new facilities. In contrast, in newly constructed airports, especially the terminal buildings, the annual maintenance cost was estimated to be $150,000 \$$ year, as shown in Table 5. During the current analyses, the construction period is considered from 2020 to 2022, while the remaining time from 2023 to 2038 represents the operation period in which the annual maintenance costs must be considered. 
Table 4. The required cost for basic operational facilities in the selected airports

\begin{tabular}{llllllll}
\hline No & Airport & Runway cost \$ & Taxiway cost \$ & Apron cost \$ & Terminal cost \$ & roads cost \$ & Total Cost \$ \\
\hline 1 & Habbaniyah & $\checkmark$ & $\checkmark$ & $\checkmark$ & $61,200,000$ & 900,000 & $62,100,000$ \\
2 & Balad & 720,000 & $\checkmark$ & $\checkmark$ & $61,200,000$ & $3,900,000$ & $65,820,000$ \\
3 & Baghdad & $\checkmark$ & $\checkmark$ & $\checkmark$ & $\checkmark$ & $\checkmark$ & 0 \\
4 & Baquba & $25,920,000$ & $9,448,800$ & $5,271,616$ & $61,200,000$ & $1,500,000$ & $103,340,416$ \\
\hline \multicolumn{7}{c}{ V: Already avilable, runway construction cost 7200 \$/m, road construction cost: 150000 \$/km }
\end{tabular}

Table 5. The annual maintenance costs for each airport

\begin{tabular}{|c|c|c|c|}
\hline No: & $\begin{array}{c}\text { Name of } \\
\text { airport }\end{array}$ & Governorate & $\begin{array}{c}\text { Annual maintenance } \\
\text { costs } \$\end{array}$ \\
\hline 1 & Baquba airport & Diyala & 150,000 \\
\hline 2 & $\begin{array}{l}\text { Habbaniyah } \\
\text { airport }\end{array}$ & AL Anbar & 300,000 \\
\hline 3 & Balad airport & Salah al Din & 300,000 \\
\hline
\end{tabular}

The discount rate of $8 \%$ is implemented to reduce the annual costs to the base year on which the comparison between these airports was done. It is calculated according to the following equation [21]:

$$
D C=A\left(\frac{1}{(1+i)^{n}}\right)
$$

\subsection{Road user costs}

The road user costs (RUCs) included the vehicle operation costs (VOCs), travel time cost (TTC), and both depend on the number of passengers using the road to arrive at the proposed airport. The vehicle operation cost consisted of fuel cost, tire cost, and vehicle annual maintenance cost. The total vehicle cost was considered as $0.0263 \$ / \mathrm{km}$ [19]. The total airport cost represented the construction cost discounted to the base year plus the annual maintenance costs for 2023 to 2038 also discounted to the base year. The road user cost for the estimated passengers for the same fifteen-year period was also discounted to the base year. The summation of wholly discounted costs to the same base year indicated an ideal comparison between these potential airports - the total costs for the best airport in the middle of Iraq listed in Table 6 .

Table 6. Total costs for the airport in the middle region of Iraq

\begin{tabular}{|c|c|c|c|c|c|c|}
\hline NO & Airport & governorate & Construction cost $(\$)^{*}$ & Road user cost $(\$) *$ & Maintenance cost $(\$)^{*}$ & Total cost $(\$)^{*}$ \\
\hline 2 & Balad & Salah al-Din & $44,820,000$ & $48,594,628$ & $4,800,000$ & $98,214,628$ \\
\hline 4 & Baquba & Diyala & $92,799,616$ & $43,800,176$ & $2,400,000$ & $138,999,792$ \\
\hline 9 & Habbaniyah & Al-Anbar & $62,100,000$ & $60,630,730$ & $4,800,000$ & $127,530,730$ \\
\hline
\end{tabular}

Table 7. Feasibility Index for best airport in the middle of Iraq

\begin{tabular}{ccccc}
\hline No. & Airport & Total cost\$ & Expected passengers & Feasibility Index \\
\hline 1 & Balad & $98,214,628$ & $14,633,605$ & 6.711 \\
2 & Habbaniyah & $127,530,730$ & $14,704,884$ & 8.672 \\
3 & Baquba & $138,999,792$ & $15,364,084$ & 9.047 \\
\hline
\end{tabular}

The feasibility index for each airport, as stated earlier, is calculated by dividing the total discount cost of any airport by the total accumulated number of passengers expected to use it during the fifteen years design period.

Table 7 shows the feasibility index for the three selected airports, in which they are arranged in descending order in terms of the total cost and total passengers. It is clear that Balad airport has the least index of 6.71 , the Habbaniyah comes next with a feasibility index of 8.672 , while the highest is the Baqubah airport which has a feasibility index of 9.047.

\section{SUMMARY OF THE MIDDLE REGION MODLE}

The emergence of the secondary airports was commenced when the core airport attained its maximum capacity of passenger numbers. The emergence of the first secondary airport equation was evaluated as below:

$$
\begin{gathered}
\text { change in airport persuasion rate= (airport } \\
\text { persuasion gap/TIME TO CHANGE } \\
\text { PERSUASION)*IF THEN ELSE(BIAP } \\
\text { passengers }<=5 \mathrm{e}+06,0,1)
\end{gathered}
$$

It was demonstrated that Balad airport was selected as the best and first airport to emerge in the middle region among the selected airports based on the least feasibility index obtained from Table 6 and the passenger persuasion and the expected number of passengers as depicted by Figures 11 and 12. Based on the above findings, Balad airport was evaluated as below:

$$
\begin{gathered}
\text { change in Balad persuasion rate }=(\text { Balad persuasion } \\
\text { gap/TIME TO CHANGE PERSUASION)*IF THEN } \\
\text { ELSE(BIAP passengers }<=5 \mathrm{e}+06,0,1)
\end{gathered}
$$

Habbaniyah airport was selected as the second airport to emerge in the middle region among the selected airports based on the least feasibility index obtained from Table 8 and the passenger persuasion and the expected number of passengers as depicted by Figures 11 and 12. The emergence of Habbaniyah airport equation was evaluated as below:

change in Habbaniyah persuasion rate $=$

(Habbaniyah persuasion gap/TIME TO CHANGE PERSUASION)*IF THEN ELSE(Balad airport

$$
\text { passengers }<=1 \mathrm{e}+06,0,1)
$$

Baquba airport was selected as the third airport to emerge in the middle region among the selected airports based on the least feasibility index obtained from Table 6 and the passenger 
persuasion and the expected number of passengers as depicted by Figures 12 and 13. The emergence of Baquba airport equation was evaluated as below:

change in Baquba persuasion rate $=$ (persuasion gap/TIME TO CHANGE PERSUASION)*IF THEN ELSE(Habbaniyah airport passengers $<=1 \mathrm{e}+06,0,1$ )

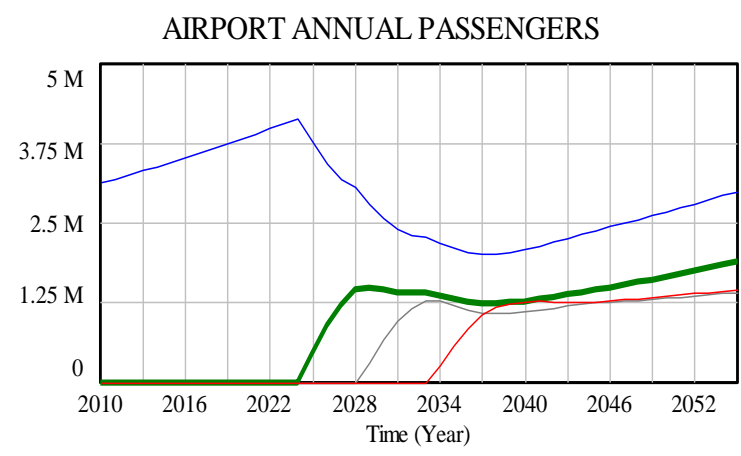

BIAP passengers : Current.vdfx

Baquba airport passengers : Current.vdfx

Balad airport passengers : Current.vdfx

Habbaniyah airport passengers : Current.vdfx

Figure 13. Annual passengers of the best airports in the middle of Iraq model

\section{RESULTS AND DISCUSSION}

The emergence of airports in the middle region in Iraq was investigated in three governorates as Salah Al-Din, Diyala, and Al-Anbar. The best airport was selected from each governorate based on the least feasibility index, and the expected number of passengers, Balad airport from Salah Al-
Din city was selected as the best airport since it recorded the least feasibility index. It was the first airport among the selected airports in this study to be nominated as the first airport to emerge in the middle region. Balad airport infrastructure was already established, but the maintenance cost needed for the airport was high. Habbaniyah was selected from Al-Anbar as the second airport to emerge in the middle region when Balad airport becomes saturated and approaches its maximum capacity. Similarly, Baquba airport was selected from Diyala governorate as the third airport to engage when Balad and Habbaniyah airports become saturated. An extensive economic analysis was done in this research to select the best airport among the selected ones. Balad airport was selected as the best airport to emerge in the middle region in Iraq in 2024. Habbaniyah airport was the second to emerge in 2028. Baquba airport will emerge in 2033 The sequence of the airports' emergence will be illustrated as below:

- Balad airport will emerge in the middle region of Iraq in 2024 because BIAP will become saturated and congested.

- Habbaniyah airport will emerge in 2028 because Balad airport will become saturated and congested, as evidenced in Figure 11.

- Baquba airport will emerge in 2033 because Balad and Habbaniyah will become full, as shown in Figure 11.

Table 8 shows the expected passengers number for the selected airports from 2023 to 2050. The expected passenger in Balad airport will emerge in the airport in 2024. The expected number of passengers of Habbaniyah airport will begin to shift from Balad airport to Habbaniyah airport in 2028. The expected number of passengers will grow at Baquba airport in 2033 when Habbaniyah airport becomes full, as shown in Table 8.

Table 8. Number of passengers of the selected airport in the middle region of Iraq

\begin{tabular}{ccccc}
\hline years & BIAP & Balad airport & Habbaniyah airport & Baquba airport \\
\hline 2023 & 4145546 & 0 & 0 & 0 \\
2024 & 3798136 & 431985 & 0 & 0 \\
2025 & 3424136 & 892278 & 0 & 0 \\
2026 & 3189806 & 1214666 & 0 & 0 \\
2027 & 3054666 & 1439656 & 0 & 0 \\
2028 & 2800706 & 1470826 & 314475 & 0 \\
2029 & 2567786 & 1443936 & 667842 & 0 \\
2030 & 2402486 & 1413116 & 959425 & 0 \\
2031 & 2311256 & 1397876 & 1163316 & 0 \\
2032 & 2284366 & 1402696 & 1284776 & 261400 \\
2033 & 2189906 & 1352536 & 1269416 & 575028 \\
2034 & 2098786 & 1298386 & 1204566 & 848357 \\
2035 & 2036816 & 1258526 & 1138666 & 1049216 \\
2036 & 2009446 & 1237576 & 1093896 & 1176256 \\
2037 & 2013186 & 1234406 & 1076236 & 1242886 \\
2038 & 2041126 & 1245736 & 1082546 & 1267796 \\
2039 & 2085756 & 1267776 & 1105446 & 1269266 \\
2040 & 2140456 & 1297116 & 1136756 & 1261916 \\
2041 & 2200156 & 1331046 & 1169696 & 1255506 \\
2042 & 2261446 & 1367646 & 1199846 & 1255126 \\
2043 & 2322446 & 1405756 & 1225246 & 1262196 \\
2044 & 2382416 & 1444786 & 1245846 & 1275776 \\
2045 & 2441366 & 1484526 & 1262796 & 1277666 \\
2046 & 2499746 & 1525036 & 1291916 & 066 \\
2047 & 2558116 & 1566486 & 1306596 & 0 \\
2048 & 2617036 & 1609046 & & 0 \\
\hline
\end{tabular}




\section{CONCLUSIONS AND RECOMMENDATIONS}

Based on the above investigations, the following conclusions will drown:

- Congestion in BIAP will start when the annual passengers reach $85 \%$ of the current 5.53 million passengers per year. It is likely to occur in 2023, according to system dynamic outcomes. It is believed that secondary airports are not likely to emerge close to a core airport with high connecting traffic unless it competes on a location advantage basis and re-emerges from an original core airport. Therefore, the emergence of the secondary airports in the middle region of Iraq was an essential need to satisfy passengers' rapid growth demand and avoid congestion.

- It was concluded that the novel system dynamic has perfectly simulated the expected passenger's number and the airport persuasion for the selected airports. Three airports were screened from nine airports in the middle region of Iraq based on the least feasibility index obtained from the system dynamic and passenger persuasion. Balad airports in salah al-Din governorate occupied the first position, Habbaniyah airport in ALAnbar governorate were in the second position and Baquba airports in Diyala Governorate were in the third position. Those airports were nominated to emerge in the middle regions starting from 2023 until 2050.

- The prospectus number of the passenger was successfully predicted using the system dynamic for the selected airports in the study territory. It was concluded that the expected number of passengers from 2023 to 2038 BIAP,Balad airport, Habbaniyah airport, and Baquba were $30,810,756 ; 14,633,605 ; 15,364,084$; and $14,704,884$, respectively.

- The time of emergence was predicted using the system dynamic from 2023 to 2050.Balad airport will emerge in 2024 when BIAP airport becomes congested, Habbaniyah airport will emerge in 2028 when Balad airport becomes congested. Baquba airport will emerge in 2033 when Habbaniyah airports reached their maximum capacity.

- These airports can add significant amount of capacity to the system in addition to enhancing people's access to air transportation. Acknowledging that secondary airports will be key mechanisms for meeting future demand for air transportation, there is a real need for establishing national and regional strategic plans for the development of regional airport systems.

- The future secondary airports are to be found in metropolitan areas where the core airports are reaching saturation and capacity adjustments are limited like Basrah, Mosul, and Erbil Because of the high barriers to new airport construction, most of new secondary airports are likely emerge from existing underutilized regional airports.

\section{REFERENCES}

[1] Jrew, B., Hussein, N.M., Al-Kouz, R. (2018). Management of multi-lane highways in Jordan (case study). Jordan Journal of Civil Engineering (JJCE), 12(1): 10-21.

[2] Al Nuaimi, E., Al Neyadi, H., Mohamed, N., Al- Jaroodi,
J. (2015). Applications of big data to smart cities. Journal of Internet Services and Applications, 6(1): 25. https://doi.org/10.1186/s13174-015-0041-5

[3] Alghadeir, A., Al-Sakran, H. (2016). Smart airport architecture using internet of things. International Journal of Innovative Research in Computer Science \& Technology (IJIRCST), 4(5): 148-155.

[4] Barros, C.P., Liang, Q.B., Peypoch, N. (2013). The technical efficiency of US airlines. Transp. Res. A Policy Pract., 50: 139-148. http://dx.doi.org/10.1016/j.tra.2013.01.019

[5] Mehta, R., Rice, S., Deaton, J., Winter, S.R. (2019). Creating a prediction model of passenger preference between low cost and legacy airlines. Transportation Research Interdisciplinary Perspectives, 3: 100075. https://doi.org/10.1016/j.trip.2019.100075

[6] Ahmadzade, F. (2010). Model for forecasting passenger of airport. Proceedings of the 2010 International Conference on Industrial Engineering and Operations Management Dhaka, Bangladesh, January 9 - 10, 2010.

[7] Tsui, W.H.K., Balli, H.O., Gilbey, A., Gowa, H. (2014). Forecasting of Hong Kong airport's passenger throughput. Tourism Management, 42: 62-76. https://doi.org/10.1016/j.tourman.2013.10.008

[8] Pierson, K., Sterman, J.D. (2013). Cyclical dynamics of airline industry earnings. System Dynamics Review, 29(3): 129-156. https://doi.org/10.1002/sdr.1501

[9] Sgouridis, S., Bonnefoy, P.A., Hansman, R.J. (2011). Air transportation in a carbon constrained world: Long-term dynamics of policies and strategies for mitigating the carbon footprint of commercial aviation. Transportation Research Part A, 45(10): 1077-1091. https://doi.org/10.1016/j.tra.2010.03.019

[10] Manataki, I.E., Zografos, K.G. (2010). Assessing airport terminal performance using a system dynamics model. Journal of Air Transport Management, 16(2): 86-93. http://dx.doi.org/10.1016/j.jairtraman.2009.10.007

[11] Sgouridis, S., Bonnefoy, P.A., Hansman, R.J. (2011). Air transportation in a carbon-constrained world: Long-term dynamics of policies and strategies for mitigating the carbon footprint of commercial aviation. Transportation Research Part A, 45(10): 1077-1091. https://doi.org/10.1016/j.tra.2010.03.019

[12] Yuliawati, E., Hadiwardoyo, S.P., Susantono, B., Tjahjono, T. (2015). System dynamic model for airport characterization in hub and spoke networks. International Journal of Technology, 6(5): 733-742. https://doi.org/10.14716/ijtech.v6i5.1039

[13] Suryani, E., Chou, S.Y., Chen, C.H. (2012). Dynamic simulation model of air cargo demand forecast and terminal capacity planning. Simulation Modelling Practice and Theory, 28: 27-41. https://doi.org/10.1016/j.simpat.2012.05.012

[14] Shang, Y., Dunson, D., Song, J.S. (2017). Exploiting big data in logistics risk assessment via Bayesian nonparametrics. Operations Research, 65(6): 1574-1588. https://doi.org/10.1287/opre.2017.1612

[15] Xue, Z., Wang, Z., Ettl, M. (2015). Pricing personalized bundles: A new approach and an empirical study. Manufacturing \& Service Operations Management, 18(1): 51-68. https://doi.org/10.1287/msom.2015.0563

[16] Tee, Y.Y., Zhong, Z.W. (2018). Modelling and simulation studies of the runway capacity of Changi Airport. Aeronaut. J. 2018, 122(1253): 1022-1037. 
https://doi.org/10.1017/aer.2018.48

[17] C`okorilo, O. (2013). Human factor modelling for fasttime simulations in aviation. Aircr. Eng. Aerosp. Technol., 85(5): 389-405. https://doi.org/10.1108/AEAT-07-2012-0120

[18] Potente, C., Ragnoli, A., Tamasi, G., Vergari, R. (2018). Quantitative risk assessment of temporary hazards and maintenance worksites in the airport safety areas: A case study. Transp. Res. Procedia, 35: 166-175. http://dx.doi.org/10.1016/j.trpro.2018.12.031

[19] Horonjeff, R., McKelvey, F.X., Sproule, W.J., Young, S.B. (2010). Planning and Design of Airports. Fifth edition, Mc grow Hill Publisher, ISBN 978-0-07164255-2.

[20] International Air Transport Association. (IATA). (2014). Fact sheet: Single European Sky (SES). http://www.iata.org/pressroom/facts_figures/fact_sheets /pages/ses.aspx, accessed on May 20, 2014.

[21] Energy technology system analyses programs. (2011). Retrived from https://iea-etsap.org/.

[22] Suryani, E., Chou, S.Y., Chen, C.H. (2010). Air passenger demand forecasting and passenger terminal capacity expansion: system dynamics framework. Expert Systems with Applications, 37(3): 2324-2339. https://doi.org/10.1016/j.eswa.2009.07.041.

[23] Zehawi, R.N. (2015). Regression sharing model development to estimate the iraqi local airports future demand. Diyala Journal of Engineering Sciences. Second Engineering Scientific Conference. pp. 20-28.

[24] Abed, S.Y., Ba-Fail, A.O., Jasimuddin, S.M. (2001). An econometric analysis of international air travel demand in Saudi Arabia. Journal of Air Transport Management, 7(3): $\quad$ 143-148. $\quad$ https://doi.org/10.1016/S09696997(00)00043-0

[25] Zehawi, R.N., Hameed, A.H., Kareem, Y.N.A. (2016). Forecasting future demand in two of the busiest us airports using simplified models. Diyala Journal of Engineering Sciences, 9(4): 93-103. https://doi.org/10.24237/djes.2016.09409.

[26] Zehawi, R.N. (2012). Development of Iraqi airport system plan. http://erepository.cu.edu.eg/index.php/cutheses/thesis/vi ew/9703.

[27] Bonneyfoy, P.A., Hansman, J.R. (2005). Emergence of secondary airports and dynamics of regional airport systems in the United States. S.M. Thesis, Department of Aeronautics and Astronautics, Massachusetts Institute of Technology, Cambridge, MA. http://hdl.handle.net/1721.1/34908

[28] Zehawi, R.N., Omar, O.O., Gadallah, A.A. (2012). Optimizing future performance for the Iraqi airport system by using a system dynamics approach. Journal of Engineering and Applied Science, 59(4): 323-341. 